5

\title{
IJUSPLAB: \\ ORIGEM, EVOLUÇÃO E PERSPECTIVAS \\ DO PRIMEIRO LABORATÓRIO DE INOVAÇÃO \\ DO PODER JUDICIÁRIO
}

\section{IJUSPLAB: \\ GENESIS, EVOLUTION AND PERSPECTIVES \\ OF THE JUDICIARY FIRST INNOVATION LAB}

Paulo Cezar Neves Junior*

\begin{abstract}
RESUMO
O objetivo deste capítulo é o de transmitir informaçôes sobre a gênese, as dificuldades, os caminhos escolhidos, os resultados alcançados até o momento e a visão de futuro do iJuspLab, o primeiro Laboratório de Inovação do Poder Judiciário, permitindo ao leitor conhecer detalhes que poderão ser úteis para a criação e o desenvolvimento de seus próprios laboratórios e experiências na inovação em governo.
\end{abstract}

Palavras-chave: iJuspLab; Justiça Federal; Poder Judiciário; Inovação; Laboratório.

\section{ABSTRACT}

The purpose of this chapter is to deliver information about the genesis, difficulties, paths chosen, the results achieved so far and

\footnotetext{
Doutorando em Direito pela Universidade de São Paulo. Mestre pela Pontifícia Universidade Católica de São Paulo. Especialista pela Universidade Federal de Santa Catarina. Graduado em Direito pela Universidade de São Paulo. Juiz Federal. Diretor do Foro da Justiça Federal do Estado de São Paulo (2016/2018). Cofundador, juntamente com a Juíza Federal Luciana Ortiz T. C. Zanoni, do Laboratório de Inovação da Justiça Federal, e seu atual coordenador. E-mail para contato: pcneves@hotmail.com.
} 
•- Inovação no Judiciário

the future vision of iJuspLab, the first Judiciary Innovation Lab, allowing the reader to know details that may be useful for the creation and development of their own laboratories and experiences in government innovation.

Keyword: iJuspLab; Federal Justice; Judicial Power; Innovation; Laboratory.

\section{ORIGEM}

No início de 2016, a Justiça Federal de São Paulo deu início a um ambicioso programa de gestão e inovação como forma de solucionar um conjunto de problemas que nos desafiavam, os quais, como se verá, são em sua maioria comuns aos dos serviços públicos em geral.

Além dos cortes orçamentários sofridos em razão da crise econômico-financeira que atingia a economia brasileira desde $2014^{1}$, e que impunham uma drástica redução de nossas despesas correntes, enfrentávamos na administração judiciária vários outros problemas.

Em síntese, não tínhamos informações detalhadas sobre a alocação de nossos recursos, a comunicação entre nossos órgãos era muito precária e não havia planejamento orçamentário, financeiro ou administrativo.

Ademais, a administração judiciária estava centralizada na figura de uma única pessoa ${ }^{2}$, que normalmente não tinha formação técnica específica para a gestão, acarretando uma personalização excessiva.

Como resultado, tínhamos uma verdadeira gestão de gabinete, ou seja, uma forma de administrar concentrada, normalmente sem planejamento e com decisóes tomadas sem ouvir usuários, os demais impactados e nem mesmo os executores diretos das medidas. As soluçôes eram implementadas sem testes prévios e normalmente de forma improvisada e emergencial.

1 A crise econômico-financeira de meados dos anos 2000 provocou retração do Produto Interno Bruto do Brasil nos anos 2014, 2015 e 2016 (para mais dados, acesse: <http://www.ipeadata. gov.br/exibeserie. aspx? serid $=38414>$.

2 A Justiça Federal de primeiro grau é dividida em seçôes judiciárias, correspondentes aos estados federados e sua administração é dirigida pelo chamado "juiz diretor do foro da seção judiciária”, que possui grande autonomia financeira e administrativa. Esta organização é feita principalmente pela Lei n. 5.010/66. Disponível em: <http://www.planalto.gov.br/ccivil_03/ leis/L5010.htm>. 
Não podemos deixar de registrar que muitas melhorias haviam sido alcançadas por meio de iniciativas de gestôes anteriores da Justiça Federal de São Paulo, mas esses problemas relatados ainda permaneciam.

$\mathrm{Na}$ verdade, observamos que muitas dessas medidas anteriores haviam sido simplesmente perdidas no tempo, superadas pela burocracia ou não continuadas em razão da personalização das gestões.

Por sua vez, o Conselho Nacional de Justiça e os Tribunais Regionais Federais também buscaram aperfeiçoar a administração judiciária desde o início dos anos 2000, implementando, por exemplo, departamentos de Gestão Estratégica e Escritórios de Projetos, trabalhos de levantamento de dados estatísticos que possibilitam o mapeamento quantitativo das atividades da Justiça Federal de $1^{\circ}$ e $2^{\circ}$ Graus e um sistema de governança colaborativa.

No entanto, esse conjunto de ações não estavam alcançando resultados práticos satisfatórios na base, uma vez que também as decisões nessa esfera repetiam os equívocos antes narrados. O ciclo da política pública judiciária era definido sem a participação efetiva de todos, mas apenas a partir de decisões de cúpula no modelo top-down, ou seja, de cima para baixo, sem colaboração e sem ouvir efetivamente as bases (magistrados e servidores de primeira instância).

Diante disso, buscamos identificar as causas desses problemas, aprender com as boas práticas e com os equívocos dos antecessores e, de forma coletiva, construímos um programa de gestão, que se denominou iNovaJusp ${ }^{3}$ (Programa de Gestão e Inovação da Justiça Federal de São Paulo).

O iNovaJusp nasceu da compreensão de que os complexos problemas da Justiça Federal de São Paulo somente poderiam ser superados por meio de um conjunto de medidas construídas de forma coletiva e planejada, focando no usuário e sem personalizações de projetos, com registros de erros e acertos, e reconhecendo e aproveitando os méritos e ideias das gestôes anteriores.

O Tribunal Regional Federal da $3^{a}$ Região apoiou e incentivou de maneira decisiva o Programa desde o seu início, o que foi fundamental para sua efetiva implementação.

3 Para saber mais acesse: <http://www.jfsp.jus.br/inovajusp/>. 
•• Inovação no Judiciário

Figura 1. Imagens do lançamento do Programa iNovaJusp.
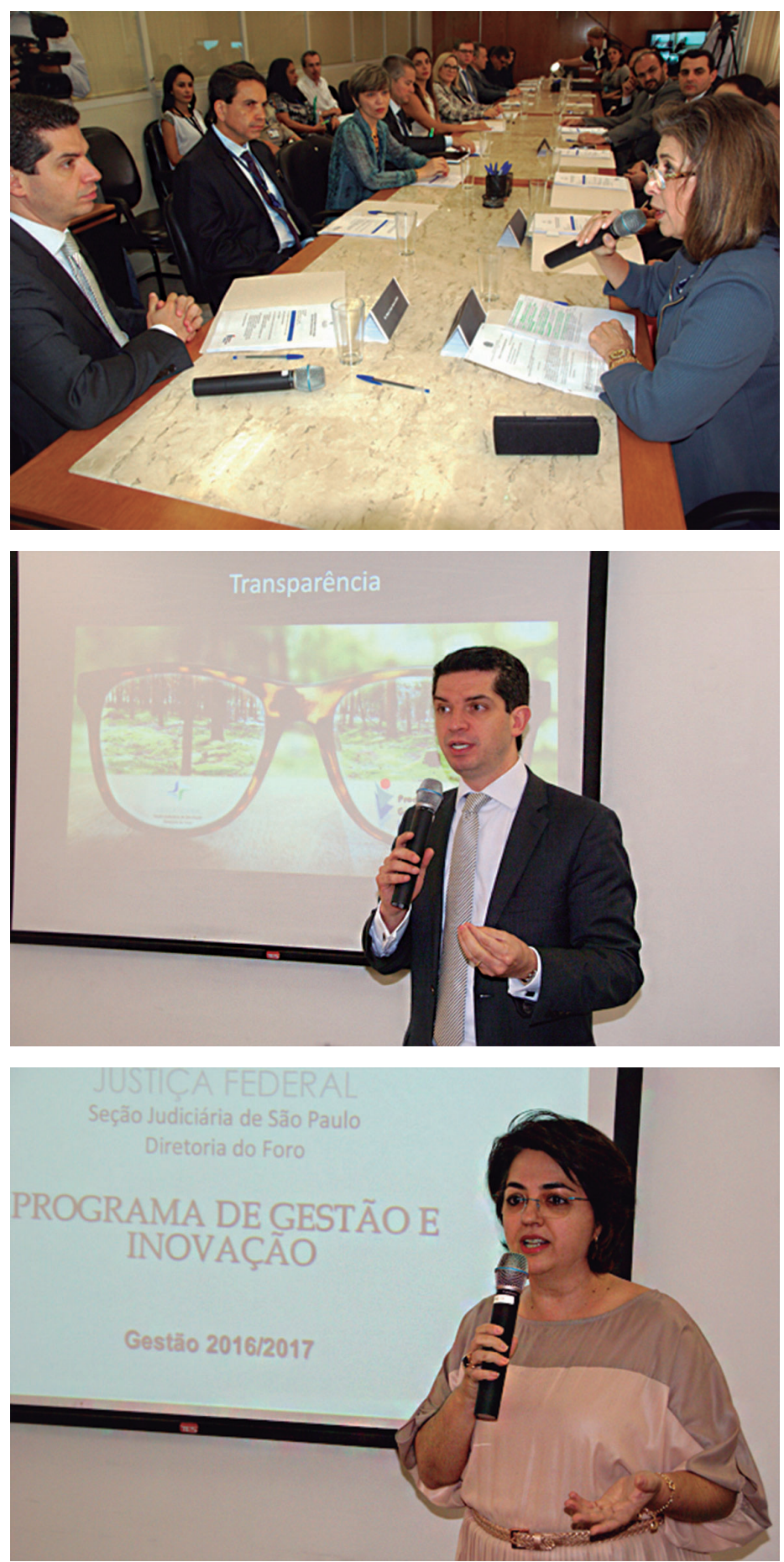

Fonte: Acervo da autoria. 
O Programa era baseado inicialmente no tripé: governança em rede, gestão estratégica e gestão da inovação. Posteriormente, considerando a necessidade de sistematizar o levantamento de dados por indicadores para realização de gestão por resultados e o crescente uso de novas tecnologias na administração, destacou-se também como fundamento do Programa a gestão de dados, com a criação de uma equipe específica e de uma incubadora de soluções tecnológicas ${ }^{4}$.

Aliás, essa é uma das principais características do iNovaJusp, que foi concebido apenas como um início de um amplo processo que deverá ser aprimorado por seus próprios participantes a partir da perspectiva do cidadão, usuário dos nossos serviços, bem como com a contribuição de todos os operadores do direito a fim de que possamos atender às suas expectativas. Trata-se de uma constante "versão beta”, que está, então, sempre em aperfeiçoamento.

Em linhas gerais, o Programa iNovaJusp tem como valores: a busca do conhecimento e inovação; a participação e integração entre a atividade-fim e a atividade-meio; o usuário do serviço no centro da gestão; a transparência de dados; a profissionalização do serviço; a co-criação nos projetos de interesse, envolvendo atores diversos dentro e fora da Administração; a visão multidisciplinar sobre os problemas; a utilização de metodologias de design, experimentação e avaliação; a flexibilidade e a desburocratização; a prototipagem, coleta de feedbacks e o refinamento de soluções.

A gestão da inovação foi então adotada justamente como forma de administrar por meio do conhecimento plural; da ampla participação de magistrados, servidores e da sociedade; da empatia na construção de soluções a partir das expectativas dos usuários do serviço; da remodelação dos serviços com base nos anseios e necessidades de seus usuários; bem como da experimentação prévia das novas ideias com o fim de promover o constante aprimoramento da prestação jurisdicional seguindo os avanços tecnológicos, acadêmicos e sociais.

A inovação é, assim, a alma do Programa e, portanto, sua parte imaterial, tendo o Laboratório de Inovação como sua principal expressão material e visível.

De fato, a criação do iJuspLab, o Laboratório de Inovação da Justiça Federal de São Paulo foi muito importante não apenas como o principal local para o desenvolvimento das atividades inovadoras da Justiça Federal, mas funcionou como um

4 Veja todos os atos normativos que estruturam o programa em: <http://www.jfsp.jus.br/inovajusp/atos-normativos/>. 
•• Inovação no Judiciário

verdadeiro símbolo da inovação do Judiciário, transmitindo uma clara mensagem de que algo diferente seria feito naquele novo ambiente totalmente distinto dos demais existentes nos tradicionais e hierarquizados fóruns e tribunais.

O iJuspLab foi concebido como um espaço de produção provido de instalações e equipamentos próprios para estudos, pesquisas, criação e desenvolvimento de projetos e programas, com uso de metodologias e técnicas colaborativas que propiciem a resolução de problemas complexos, tais como design thinking, modelagem de serviços e uso de plataformas de inovação aberta; oficinas para a resolução de problemas concretos do âmbito da atuação governamental; apoio à gestão, lançamento e maturação de projetos, envolvendo ações de coaching, realização de pilotos e de modelagem de estrutura de gestão, tomando como paradigma o Laboratório de Inovação em Governo - iGovLab, do governo do Estado de São Paulo.

Muito importante destacar que, ao tomarmos a decisão de termos um laboratório de inovação, precisávamos pensar nele não apenas como um espaço novo que despertasse a criatividade. Isso porque correríamos o risco de não sabermos o que fazer com ele após sua inauguração. Era imprescindível termos uma definição clara dos motivos pelos quais teríamos um laboratório de inovação em nossa instituição e também teríamos de estabelecer o conjunto inicial de serviços por ele prestados, com quem ele funcionaria (equipes de trabalho) e como seria sua utilização (regras de governança).

Em nosso caso, o desafio inicial era ainda o de conseguirmos recursos financeiros para a construção de nosso laboratório. Isso porque, como dissemos acima, as restrições orçamentárias eram grandes naquela época.

Mas foi justamente essa dificuldade que começou a nos ensinar como trabalhar com as técnicas da inovação mesmo de forma ainda intuitiva.

Assim, reunimos servidores de diversas áreas, tais como arquitetura, engenharia, almoxarifado, comunicação visual, informática, dentre outras, e iniciamos um planejamento coletivo por meio de estudos sobre laboratórios de inovação e dos meios de que dispúnhamos para isso naquele momento.

Conversamos com pessoas com experiência nessa área para termos orientações práticas importantes nessas decisões envolvendo desde o tamanho do laboratório até mesmo quais os equipamentos e instrumentos imprescindíveis para seu funcionamento. 
Esta etapa de planejamento é muito importante porque não bastaria olharmos fotos e desenhos desses espaços modernos de coworking para compreendermos o que precisaríamos ter em nosso laboratório de inovação.

Além desse trabalho em grupo, foi imprescindível o apoio financeiro que recebemos da Associação dos Juízes Federais de São Paulo e Mato Grosso do Sul (Ajufesp) para a aquisição de móveis e de parte de materiais para a reforma da sala em que o laboratório foi instalado.

Como se viu, desde o início, tivemos uma verdadeira construção coletiva do iJuspLab, mas, por outro lado, podemos dizer que não são necessários gastos elevados para se ter um laboratório de inovação. Muito foi feito por meio de reutilização de materiais permanentes, como móveis e equipamentos eletrônicos (televisores, telas e projetores), bem como com a utilização de nossos próprios servidores e colaboradores.

Figura 2. Fotos da reforma.
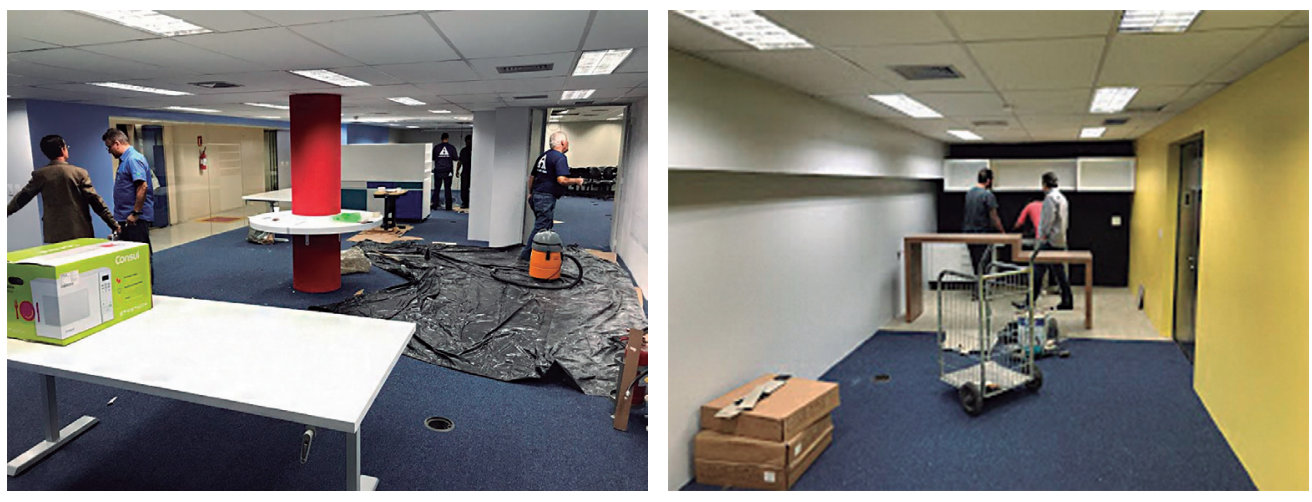

Fonte: Acervo da autoria.

Enquanto o iJuspLab tomava corpo, planejamos o treinamento de nossa equipe de inovação.

Este é outro tema importantíssimo neste trabalho. E aqui, muitas dúvidas tivemos.

Num primeiro momento, caminhávamos para uma contratação de uma orientação de dinâmica com utilização das técnicas de design thinking e, ao final, um grande evento de inovação aberta (hackaton).

No entanto, percebemos que o melhor a fazer naquele início era trabalharmos diretamente não num grande projeto, mas na capacitação de um grupo de 
•- Inovação no Judiciário

servidores a fim de termos em nosso laboratório uma equipe preparada para conduzir os projetos do início ao fim, ou seja, precisávamos conquistar uma independência para termos maior capacidade e velocidade na condução dos trabalhos no laboratório.

Afinal, se dependêssemos sempre de algum instrutor ou mentor externo para conduzir e orientar nossos trabalhos, teríamos um custo fixo constante e uma maior demora para iniciarmos cada novo projeto no laboratório.

Assim foi feito.

\section{DESENVOLVIMENTO}

Iniciamos um curso de capacitação de nossos laboratoristas para que iniciassem seus conhecimentos em design thinking, metodologia escolhida para a realização de nossos trabalhos no iJuspLab.

Este curso inicial reuniu cerca de 25 pessoas no formato "aprendendo fazendo" (learn by doing).

Além de permitir o treinamento inicial de servidores e magistrados nessa metodologia, o curso despertou em várias pessoas a vontade de integrar a equipe de inovação da Justiça Federal de São Paulo, sendo que quatro delas continuaram a se dedicar a esses estudos (Elaine Cristina Cestari, Gisele Molinari Fessore, Helio C. Martins Jr. e Luiz Guilherme Martins ${ }^{5}$ ). Este grupo é até hoje o núcleo de nosso time de inovação.

O treinamento abrangeu todas as fases do design thinking (imersão no problema, ideação de soluções e prototipagem final), tendo nele sido desenvolvidos alguns projetos iniciais. Nosso principal objetivo naquele momento não era o de alcançarmos esses projetos, mas desenvolver capacidades, identificar talentos e iniciar o empoderamento de nosso time de inovação.

Em 12 de junho de 2017, o iJuspLab foi inaugurado com a presença de inúmeras autoridades e personalidades de dentro e de fora do Judiciário, o que nos revelou que o tema da inovação no setor público despertava realmente um grande interesse na sociedade, permitindo-nos pensar em vários projetos conjuntos num futuro próximo.

Veja detalhes deste início de atividades narrados em capítulo deste livro escrito pelos próprios integrantes da Equipe de Inovação do iJuspLab. 
Figura 3. Imagens da inauguração do iJuspLab.
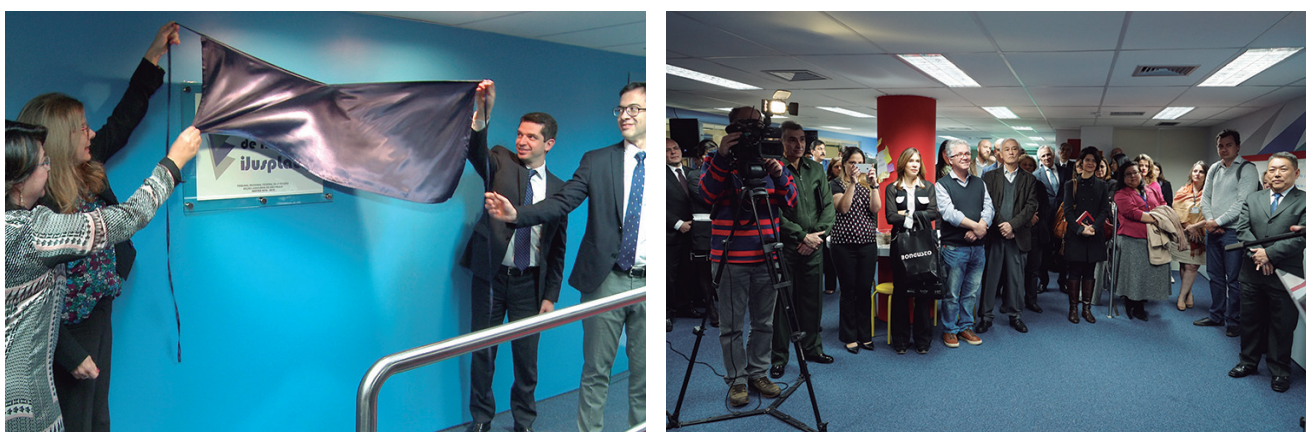

Fonte: Acervo autoral.

Com nosso laboratório de inovação inaugurado e após essa iniciação nas técnicas do design thinking, precisávamos definir suas atividades regulares e estruturar sua governança.

Para isso, realizamos mais uma capacitação executiva no formato "aprendendo fazendo", o que funcionou também como uma poderosa ferramenta de motivação de nossa equipe. Afinal, eles começavam a se sentir parte integrante e relevante da inovação na Justiça Federal, o que, de fato, eram. Eles estavam aprendendo e construindo com esses novos conhecimentos.

Com esse trabalho, definimos as vocações iniciais do nosso laboratório, redigindo, ao final, a "Carta de Serviços do iJuspLab"6, descrevendo as seguintes atividades que poderiam ser nele realizadas:

1) Disseminação da cultura da inovação: realização, promoção e divulgação de iniciativas internas e externas relacionadas à inovação no setor público.

2) Desenvolvimento de soluçóes inovadoras: auxílio e mediação na busca de soluções para problemas locais e institucionais.

3) Capacitação em metodologias colaborativas: formação de servidores para aplicação de metodologias inovadoras de solução de problemas, com uso do ferramental, bem como para atuar como multiplicadores.

4) Radar da inovação: prospecção e incentivo de notícias, artigos e vídeos sobre inovação no Brasil e no Mundo.

6 Para saber mais, acesse <http://www.jfsp.jus.br/carta/>. 
•- Inovação no Judiciário

5) Plataforma interinstitucional de inovação: participação e formação de redes de estímulo à integração entre instituições para fomento da inovação.

Naquele momento, tínhamos uma equipe de inovação começando a ganhar autoconfiança para dar seus primeiros passos e o desafio de começar a introduzir a cultura da inovação em toda a Justiça Federal de São Paulo.

Decidimos incentivar trabalhos que nos permitissem realizar entregas rápidas e com resultados práticos importantes, além de investir na comunicação desses resultados dentro e fora da Justiça Federal.

Assim, desenvolvemos, por exemplo, um trabalho de mapeamento e reavaliação de todos os fluxos de trabalho de nossa área administrativa central ${ }^{7}$, bem como uma proposta de redesenho organizacional das varas (Projeto Rede PJe ${ }^{8}$ ). Inserimos o iJuspLab na Rede Federal de Inovação (InovaGov ${ }^{9}$ ), na rede estadual de inovação $\left(\operatorname{InovaDay}^{10}\right)$, no desafio mundial de inovação $\left(G_{0}{ }^{11}\right)$ e na rede mundial de laboratórios de inovação (a partir da fundação Nesta ${ }^{12}$ ). Além disso, incentivamos magistrados e servidores a inscreverem resultados de seus trabalhos inovadores em concursos de boas práticas.

Apesar de todos esses esforços iniciais, o movimento de inovação na Justiça era ainda visto com reservas e resistências na instituição.

Esse quadro começou a mudar quando os resultados começaram a aparecer.

Além disso, nosso trabalho começou a ser reconhecido fora da instituição, inclusive no exterior.

7 Foram mapeados e revisados mais de 500 fluxos de trabalho, utilizando-se a ferramenta "Bizagi", sendo mantida a revisão periódica constantes desses fluxos mapeados.

8 Projeto de novo modelo organizacional para as varas federais solicitado pela presidência do TRF3 em 2017, que propóe a eliminação do cartório (secretarias) e reorganiza a estrutura de processamento dos feitos, mediante a criação de Centrais de Processamento Eletrônico (CPE), distribuídas pela Seção Judiciária de São Paulo, visando à otimização de recursos humanos e materiais. Dessa maneira, as varas seriam unidades com estrutura voltada quase que exclusivamente para a atividade decisória, ficando para o processamento eletrônico e para as CPEs as demais atividades, incluindo a de cumprimento de decisões judiciais.

9 <http://inova.gov.br/>.

$10<$ http://inovaday.com.br/br/>.

$11<$ http://www.govjam.org/>.

12 <http://publicsector-map.designforeurope.eu/en/> e <https://www.nesta.org.uk/>. 
O iNovaJusp foi selecionado para ser apresentado no Congresso Internacional da International Association for Court Administration (IACA) em 2017 realizado em Washington-DC/EUA e recebeu o Prêmio Ajufe Boas Práticas também naquele ano. Também foi apresentado ao embaixador do Brasil nos Estados Unidos da América, ao Federal Judicial Center e novamente selecionado para apresentar seus resultados no Congresso da IACA em 2018.

Esses fatos impactaram sensivelmente na aceitação e na credibilidade da inovação em nossa instituição.

Foi visível a mudança de postura e o crescente interesse pelo nosso Laboratório de Inovação a partir de então.

Começamos, inclusive, a receber visitas de outras instituiçôes do próprio Judiciário como as Justiças Federais do Rio Grande do Sul, Santa Catarina, Paraná, Rio de Janeiro, Espírito Santo, Brasília, Pernambuco, Rio Grande do Norte, Ceará e Amazonas; comitiva do Tribunal de Justiça de São Paulo; o Conselho Nacional de Justiça, bem como de outras instituições que não integram o Judiciário, tais como a Secretaria de Educação do Estado de São Paulo e a Procuradoria do Município de São Paulo.

Tudo isso foi fundamental para que a cultura da inovação começasse a ser incorporada por nossos magistrados e servidores. Essa cultura da inovação, aliás, começa a ganhar força inclusive fora da Justiça Federal de São Paulo, uma vez que foram criados laboratórios de inovação, por exemplo, na Justiça Federal do Rio Grande do Norte, do Espírito Santo e no Ceará, tendo o iJuspLab colaborado com todos para que uma verdadeira rede de laboratórios de inovação do Judiciário fosse criada.

Enquanto isso, nosso time de inovação avançava em seus trabalhos e começava a agregar mais pessoas.

As atividades do laboratório, principalmente as de solução de problemas complexos por meio do design thinking, funcionavam também como polo atrativo de novos talentos para nosso $i$-team.

Como não havia ainda conhecimentos específicos de inovação jurídica ("legal design") no Brasil, percebemos que o ideal seria avançarmos com nosso time de inovação por meio de experiências colaborativas com outros laboratórios de inovação em governo. Então, passamos a buscar essa interação.

Encontramos um ótimo ambiente para isso num evento chamado "HubGov", organizado pela "We Gov". Trata-se de um programa de inovação por meio do 
•• Inovação no Judiciário

qual times de vários setores ou diferentes instituições passam por uma jornada de trabalho em que desenvolvem conjuntamente uma solução inovadora para determinado problema ou desafio.

Nossa equipe de inovação avançou bastante em termos técnicos e de maturidade ao participar desses eventos multi-institucionais. Hoje, podemos dizer que temos um time de inovação que é referência no "legal design".

Além disso, o trabalho com a inovação, apesar de não se resumir a isso, aproxima-se constantemente da gestão de dados, da inteligência artificial e das novas tecnologias disponíveis e, assim, o iJuspLab expandiu suas atividades para essas áreas, criando a "Equipe de Gestão de Dados do iNovaJusp" e a "Incubadora de Soluçôes Tecnológicas"13.

Em meados de 2018, apesar de continuarmos avançando nos trabalhos do iJuspLab e investirmos em nossa comunicação, percebemos que nossos usuários internos e externos não nos estavam trazendo seus problemas, desafios e oportunidades de inovação.

Tínhamos preparado um formulário simplificado em nosso site para a apresentação de demandas, mas esse canal vinha sendo pouco utilizado. Queríamos nos aproximar de nossos usuários interno e externo.

Como estimular essa participação?

Pensamos numa conduta pró-ativa do iJuspLab. Buscaríamos nossos usuários e conversaríamos com eles. No entanto, não queríamos realizar pesquisas tradicionais para isso. Precisávamos de outra metodologia, que nos permitisse alcançar com nossos usuários um resultado mais denso, criativo e inovador nessas conversas.

Pensamos em aproveitar esse trabalho para reorganizar nosso fluxo de projetos no iJuspLab e mais: queríamos desenvolver um ciclo completo de inovação, abrangendo a prospecção de desafios, sua compreensão, seleção de prioridades e implementação das soluções encontradas.

Assim nasceu nosso Mapeamento de Oportunidades de Inovação (MOI).

Em síntese, nosso objetivo foi o de identificar problemas organizacionais e corporativos da JFSP que poderiam ser transformados em oportunidades de inovação, melhorando assim a prestação dos serviços.

13 <http://www.jfsp.jus.br/documentos/administrativo/NUID/inovajusp/atos/portaria-2018-36.pdf>. 
Este mapeamento é, na visão de alguns especialistas ${ }^{14}$, a principal missão de um laboratório de inovação, qual seja a de caracterizar e posicionar os desafios de uma entidade, mais do que solucionar problemas definidos.

Dividimos os trabalhos em quatro módulos:

1) Identificação, organização e mapeamento dos desafios.

2) Desenvolvimento de soluções de design.

3) Busca de soluções tecnológicas.

4) Implementação das soluçôes.

No primeiro módulo, nosso time de inovação realizou entrevistas desestruturadas com magistrados, servidores, terceirizados, advogados, cidadãos, enfim, usuários externos e internos dos serviços judiciários, buscando identificar problemas, desafios e oportunidades de inovação na Justiça Federal de São Paulo.

A partir daí, foram organizadas as informações colhidas, levando-se em conta fatores como o impacto social e para a instituição, o grau de inovação, complexidade e tempo estimado para implantação.

Os resultados foram divididos em três grupos: o dos problemas facilmente solucionados por meio de meras ações executivas da administração (por exemplo, fornecimento de computadores); o dos problemas que demandariam soluçôes tecnológicas (por exemplo, desenvolvimento de novos sistemas informatizados ou aprimoramento técnicos do processo judicial eletrônico); e o dos problemas que poderiam ser solucionados utilizando-se o design thinking.

Estes últimos começaram a ser trabalhados no iJuspLab, com a participação do time de inovação da JFSP, de voluntários e da empresa iLabs Services, contratada para fazer nossa capacitação e fornecer mentoria em todas essas etapas.

Os primeiros desafios trabalhados no iJuspLab nesta etapa foram:

- Tema 1 - Atendimento/Acolhimento ao cidadão.

- Tema 2 - Movimentação de servidores.

- Tema 3 - Redes de colaboração.

- Tema 4 - Incremento da participação das mulheres na carreira da magistratura.

14 CHRISTIANSEN, Jesper. The art of the innovation lab. <https://www.nesta.org.uk/blog/ the-art-of-the-innovation-lab/>. Acesso em: 15 de agosto de 2018. 
•- Inovação no Judiciário

Definiu-se que o segundo grupo de desafios (soluções tecnológicas) seria trabalhado por meio da realização de um pitch, ou seja, um concurso para que empresas nascentes (startups) trouxessem ideias para suas soluçôes.

Por fim, a implementação das soluções seria analisada pela Administração Central conforme possibilidade, oportunidade e conveniência.

Esse trabalho foi muito proveitoso e importante para que tivéssemos um fluxo bem definido para o funcionamento do iJuspLab.

Claro que sempre será possível ajustar este ciclo de atividades, incluindo em caráter emergencial, por exemplo, um novo desafio nas atividades do iJuspLab, mas termos um roteiro de atuação facilitou bastante a organização de nossos trabalhos.

Por fim, realizamos também um trabalho para avaliar o atual estado de prontidão para inovar da Justiça Federal de São Paulo com relação aos temas Governança, Métricas, Cultura, Aprendizado, Redes de Colaboração e Gestão da Informação.

Em síntese, queríamos saber:

1) Governança: se a inovação na Justiça Federal de São Paulo estava bem estruturada, com responsabilidades definidas e claramente vinculadas aos objetivos e processos estratégicos em todas as nossas áreas indo além do Laboratório de Inovação.

2) Métricas: se o modelo de gestão da Justiça Federal de São Paulo incorporava métricas claramente associadas à inovação.

3) Cultura: se a inovação estava incorporada à cultura e aos valores fundamentais da Justiça Federal de São Paulo; se os líderes da organização incentivavam ativamente a inovação e a aprendizagem organizacional.

4) Aprendizado: se nossos processos de aprendizagem e inovação eram tratados como vitais para a organização.

5) Redes de colaboração: se as redes colaborativas formais existiam e se envolviam contato com outras varas, fóruns, parceiros etc.

6) Gestão da Informação: se nosso portal corporativo estava desenvolvido com perfis bem definidos, com acesso fácil à documentos e se era a principal fonte de informação para o dia-a-dia do trabalho.

Analisando esse resultado de nosso primeiro Radar, percebemos uma clara diferença de percepção entre os grupos de servidores e de magistrados. Verificamos que nossos servidores ainda percebem a inovação como uma iniciativa num baixo nível de desenvolvimento em nossa instituição, diferentemente do que pensam 
alguns magistrados. Também identificamos que temos de aperfeiçoar nossas métricas e avançar no desenvolvimento de uma cultura de inovação. Por outro lado, a governança e a gestão da informação são compreendidas pelos magistrados como temas tratados de uma maneira razoável, mas os servidores não têm essa mesma percepção. Por fim, as redes de colaboração ainda são ainda muito fracas em nossa Instituição na percepção dos dois grupos.

Esta primeira edição do "Radar da Inovação" na Justiça Federal de São Paulo serviu para atentarmos um pouco mais para a comunicação do iJusplab com os servidores, haja vista a notória diferença de percepção e de conhecimento destes a respeito da inovação na Instituição, e servirá como referência para medirmos nossos resultados nesses diversos temas relevantes para a avaliação de todos os trabalhos realizados no iJuspLab.

Devemos repetir periodicamente essa análise a fim de termos subsídios para o aperfeiçoamento constante de nossas atividades no Laboratório.

Figura 4. Radar da informação. Cruzamento geral.

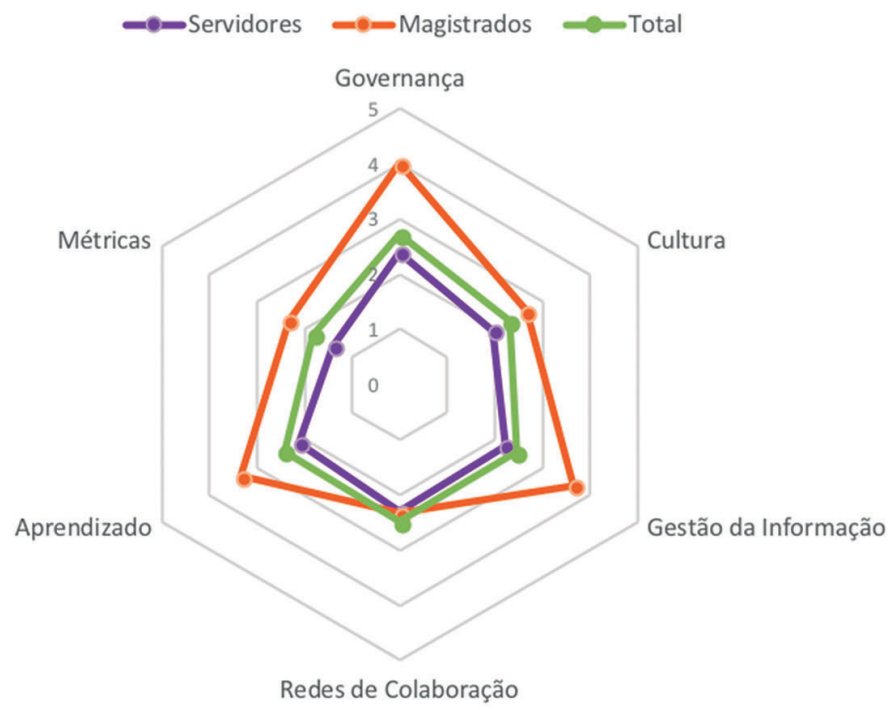

Fonte: Justiça Federal de Primeiro Grau em São Paulo.

\section{PERSPECTIVAS}

Após todas essas atividades realizadas, passados três anos do início do Programa de Gestão e Inovação da Justiça Federal de São Paulo (iNovaJusp), vemos um avanço significativo na cultura da inovação dentro do Poder Judiciário. 
•• Inovação no Judiciário

Além da criação de diversos outros laboratórios de inovação, o próprio Conselho Nacional de Justiça está investindo no uso das técnicas de inovação na gestão judiciária ${ }^{15}$, tendo, inclusive proposto Projeto de Lei que visa à "instituição do Laboratório de Inovação, Inteligência e Objetivo de Desenvolvimento Sustentável LIODS” em sua estrutura ${ }^{16}$.

O iJuspLab tem sido palco de várias atividades de cocriação para, por meio do design thinking, construir indicadores específicos da gestão judiciária que possam contribuir efetivamente para o cumprimento dos Objetivos de Desenvolvimento Sustentável da Agenda 2030 da ONU (Organização das Naçôes Unidas) ${ }^{17}$.

Como se percebe, o laboratório de inovação dentro do Poder Judiciário funcionou realmente como verdadeiro símbolo da mudança de paradigma em sua gestão, aproximando magistrados, servidores, acadêmicos e a iniciativa privada, todos convergindo para a busca da melhoria dos serviços e produtos aplicáveis ao Direito e à Jurisdiçãao. Ademais, contribuiu para um início de mudança da forma como enxergamos nossos serviços. Passamos a vê-lo na perspectiva de nossos usuários.

Isso é muito importante.

Afinal, em plena 4a Revolução Industrial, a sociedade exige também do Poder Judiciário uma nova postura diante dos complexos desafios que lhes são apresentados, o que não se resume na implementação dos chamados processos eletrônicos.

Nesta Era do Conhecimento, a sociedade exige eficiência nos serviços jurisdicionais, maior transparência e a democratização da administração judiciária.

Ademais, a Constituição Federal brasileira é expressa ao estimular a formação e o fortalecimento da inovação também nos entes públicos, bem como a constituição e a manutenção de ambientes promotores da inovação (art. 219, parágrafo único).

Essa inovação deve ser entendida como a implementação de um processo ou produto - bem ou serviço - novo ou significamente melhorado, ou de uma nova prática organizacional, de um novo espaço de trabalho ou de novas relaçóes externas, que traga como resultado sempre algum valor ou alguma utilidade nessa mudança.

\footnotetext{
15 <http://www.jfsp.jus.br/comunicacao-publica/indice-noticias/noticias-2018/10122018-ijusplab-recebe-visita-de-conselheira-do-cnj-e-estudantes/>.

16 <https://www.camara.leg.br/proposicoesWeb/prop_mostrarintegra;jsessionid=52A68BF088 B72505A35911D2EC173A62. proposicoesWebExterno1? codteor $=1701795 \&$ filename $=$ $\mathrm{PL}+11215 / 2018>$.

17 <http://inova.gov.br/ijusplab-realiza-oficina-sobre-os-ods-da-agenda-2030/>.
} 
No âmbito jurídico, todas essas formas de inovação são possíveis, tanto no âmbito privado quanto no âmbito público, podendo ser produzidas pelo Poder Judiciário, mas também pelos advogados, pelas universidades e por empresas privadas.

As técnicas da inovação permitem o avanço em basicamente três campos jurídicos: a) design - para que sejam criados e remodelados serviços e produtos jurídicos e judiciários que as pessoas precisam e desejam; b) tech - para que sejam desenvolvidas ou utilizadas tecnologias em prol da eficácia e eficiência do Direito; e c) law - para que sejam criadas e remodeladas normas jurídicas promovendo uma sociedade mais justa e engajada.

O iJuspLab quer se tornar um ponto de referência e de contribuição em todos esses campos.

De toda sorte, a inovação e o legal design se apresentam como protagonistas de uma verdadeira revolução no relacionamento entre o Poder Judiciário e a sociedade.

O iJuspLab fez bastante, mas tem ainda muito a produzir.

Os desafios são vários para que possamos ter um serviço judiciário com a presteza e a qualidade desejados e merecidos por nossa sociedade.

Por outro lado, as novas tecnologias, a inteligência artificial, a big data e ainda as novidades que sequer conhecemos, certamente se apresentam como importantes aliados nesses trabalhos.

Pensamos, de imediato, em avançarmos com o iJuspLab na pesquisa científica e empírica envolvendo os diversos atores e usuários dos serviços judiciários, mas também em parcerias com a iniciativa privada e com o meio acadêmico para unirmos todos em torno da inovação na busca do aperfeiçoamento dos nossos serviços judiciários.

Nosso objetivo final é o de não precisarmos mais de um laboratório de inovação no Poder Judiciário porque a cultura da inovação estaria incorporada totalmente a seu modo de trabalho.

\section{BIBLIOGRAFIA}

AGUNE, Roberto [et al.]. Dá pra fazer - Gestão do conhecimento e inovação em governo. São Paulo: Secretaria de Planejamento e Desenvolvimento Regional, 2014, 167p.

AMBROSE, Gavin, Paul Harris. Design thinking. Trad. Antonio Roberto Oliveira. Porto Alegre: Bookman, 2011. 
•• Inovação no Judiciário

BROWN, Tim. Design thinking: uma metodologia poderosa para decretar o fim das velhas ideias. Trad. Cristina Yamagami. Rio de Janeiro: Alta Books, 2017.

CHRISTIANSEN, Jesper. The art of the innovation lab. <https://www.nesta.org.uk/ blog/the-art-of-the-innovation-lab/>. Acesso em: 15 ago. 2018.

LIEDTKA, Jeanne. Porque o design thinking funciona. Massachusetts, EUA: Harvard Business Review, Outubro, 2018. 10p.

MELO, Adriana, Ricardo Abelheira. Design thinking \& thinking design. São Paulo: Novatec, 2015.

OECD/Eurostat (2005), Oslo Manual: Guidelines for Collecting and Interpreting Innovation Data, $3^{\text {rd }}$ Edition, The Measurement of Scientific and Technological Activities, OECD Publishing, Paris. <https://doi.org/10.1787/9789264013100-en>. 